\title{
Sodium Valproate Exacerbating an Underlying Disorder of Fatty Acid Metabolism
}

\author{
Jamie Bellinge Sanjaya Herath Dharmesh Sonigra \\ Robina Hospital, Gold Coast Health, Gold Coast, Qld., Australia
}

\section{Keywords}

Sodium valproate $\cdot$ Mitochondrial disorder $\cdot$ Rhabdomyolysis

\begin{abstract}
We describe a 29-year-old female who presented with rhabdomyolysis shortly after starting a course of sodium valproate. A thorough investigation revealed a likely mitochondrial origin inducing this susceptibility. An underlying mitochondrial disorder should be considered in all patients who present with undifferentiated disease whilst taking sodium valproate.
\end{abstract}

(C) 2016 The Author(s)

Published by S. Karger AG, Basel

\section{Introduction}

Mitochondrial respiratory chain disorders are increasingly recognised in today's era of medicine. In Australia alone, the prevalence of mitochondrial disease is now 13.1/100,000 [1], owing to the advancements in laboratory diagnostic techniques and growth in practitioner education and recognition. Often, these conditions are identified in the neonatal and paediatric age group, when patients present with some of the findings described in table $1[2]$.

Disorders of this biochemical pathway may also manifest later in life, frequently involving multiple bodily systems [3]. Organs commonly involved are those with a high concentration of mitochondria. The liver, heart, central nervous system and skeletal muscle tissue

\section{KARGER}


are typical examples. If mitochondrial disease is suspected, a skeletal muscle biopsy is indicated [4].

Sodium valproate is a frequently prescribed broad-spectrum anti-epileptic medication. It is often tolerated well with minimal side effects, though on multiple occasions it has been shown to cause life-threatening adverse events. There is a vast quantity of publishing surrounding certain patient susceptibilities to these detrimental effects. In this particular case, sodium valproate's impact on the mitochondrial respiratory chain has likely induced a lifethreating disease state in the patient reported here [5].

\section{Case Report}

We describe the case of a 29-year-old Caucasian female who presented to the emergency department with a 4-day history of acute-onset proximal muscle weakness and associated mild myalgia. A 3-week history of preceding lethargy and fatigue was also described.

Her background was significant for depression, insomnia, alcoholism and epilepsy. Her epilepsy was diagnosed at the age of 24 years with 10 tonic-clonic seizures (associated with incontinence) since diagnosis. She had experienced her last seizure approximately 12 months prior to presenting. She was initially managed with levetiracetam 1,000 mg b.d. but self-ceased this medication 6 months prior to presentation. The patient was commenced on sodium valproate $200 \mathrm{mg}$ b.d. after a 4-month medication-free period. She ceased the sodium valproate 1 week prior to presentation due to symptoms of lethargy, depression and fatigue that she attributed to the medication. She has no allergies and has never experienced an adverse drug reaction before.

The patient described multiple episodes of a similar myopathic nature occurring intermittently over the previous 4 years. These were described as extreme difficulty walking up stairs or getting out of bed. This would occur for a day or so and then resolve.

The patient denied the consumption of alcohol or illicit drugs prior to the onset of weakness, and this was confirmed by a reliable collateral history. No other precipitating factors were identified in a thorough history. Surgical history and family history were both unremarkable.

On examination, the patient appeared malnourished, underweight and pale. Her speech was slurred, and bilateral ptosis (without fatigability) was present. Her vital signs were stable, and she was afebrile. Abdominal exam revealed a mild hepatomegaly $(21 \mathrm{~cm})$ and splenomegaly $(18 \mathrm{~cm})$. There was conjunctival pallor, and multiple bruises were found on the legs.

Neuromuscular system examination revealed symmetrical bilateral proximal muscle weakness of the shoulders, hips and knees. The hips were affected the worst (2/5 power), followed by the knees ( $3 / 5$ power) and shoulders ( $4 / 5$ power). There was no involvement of distal muscles. There was muscle atrophy noted around the quadriceps and gluteal region. The patient experienced significant difficulty standing from a seating position alone, though when assisted, displayed a classical waddling gait indicative of proximal muscle weakness. The remainder of the examination was unremarkable. 


\section{Case Reports in Neurology}

\begin{tabular}{l|l}
\hline Case Rep Neurol 2016;8:185-192 \\
\hline DOI: $10.1159 / 000447087$ & $\begin{array}{l}\text { C 2016 The Author(s). Published by S. Karger AG, Basel } \\
\text { www.karger.com/crn }\end{array}$ \\
\hline
\end{tabular}

Bellinge et al:: Sodium Valproate Exacerbating an Underlying Disorder of Fatty Acid Metabolism

\section{Investigations}

A urine dipstick identified protein $(+++)$, heme $(++)$ and a dark brown colouring. In combination with the physical examination, a provisional diagnosis of rhabdomyolysis was made. This prompted the following investigations. A full blood count revealed a mild macrocytic anaemia with no indications of infection. Liver function tests were significantly deranged (ALP $195 \mathrm{IU} / \mathrm{l}$, GGT $342 \mathrm{IU} / \mathrm{l}$, ALT $347 \mathrm{IU} / \mathrm{l}$ and AST 1,460 IU/l), and INR was 1.3. In the context of the clinical scenario, the marked elevation of AST and the smaller elevation of ALT are likely a result of muscular release of these enzymes. An admission 18 months previously had shown similar results (ALP 298 IU/l, GGT 2,810 IU/l, ALT 155 IU/l and AST 179 $\mathrm{IU} / \mathrm{l}$ ), indicating a likely chronic impairment of liver function. Urine MCS and drug screen indicated no signs of infection or drug abuse. Erythrocyte sedimentation rate and C-reactive protein were $32 \mathrm{~mm} / \mathrm{h}$ and $24 \mathrm{mg} / \mathrm{l}$, respectively. Serum calcium, potassium and phosphate were within the normal ranges. The serum urea measured $5.5 \mathrm{mmol} / \mathrm{l}(2.1-7.1 \mathrm{mmol} / \mathrm{l})$, and the serum creatinine measured $42 \mu \mathrm{mol} / \mathrm{l}(46-90 \mu \mathrm{mol} / \mathrm{l})$, which resulted in a urea/ creatinine ratio of 131 (46-100). A baseline measurement from 18 months prior showed urea to be $2.9 \mathrm{mmol} / \mathrm{l}$ and creatinine to be $32 \mu \mathrm{mol} / \mathrm{l}$ with a urea/creatinine ratio of 90 . One should expect a low urea/creatinine ratio in the early stages of rhabdomyolysis when muscle release of phosphocreatinine (metabolised to creatinine) exceeds that of the serum urea. However, in later stages of rhabdomyolysis, the catabolism of muscle proteins results in an elevation of serum urea and a resulting increase in the urea/creatinine ratio. If this patient had presented earlier in her disease state, we would have likely found a significantly higher serum creatinine. A urinalysis was negative for red blood cells, suggesting (in combination with the dipstick findings) myoglobinuria. A urine myoglobin assay was performed on day 5 of admission after rigorous fluid resuscitation. The result was negative, not unexpected due to the half-life of myoglobin (1-3 h) and the significant dilution of urine. Serum glucose, thyroid function tests and serum lactate were normal. Viral serologies for HIV, hepatitis B and hepatitis $\mathrm{C}$ were negative. Rheumatoid factor, anti-nuclear antibodies, anti-MuSK antibodies and anti-acetylcholine receptor antibodies were also negative. On admission, creatine kinase was elevated to 14,600 U/l. This declined to 1,020 U/l after 5 days of treatment and resolved to normal levels by day 9 . An abdominal ultrasound confirmed hepatosplenomegaly (21 and $18 \mathrm{~cm}$ ) and identified fatty changes of the liver. An acylcarnitine assay was performed after the possibility of mitochondrial involvement was suspected (fig. 1; table 2).

\section{Discussion}

The patient was diagnosed with rhabdomyolysis and myoglobinuria. Appropriate treatment was commenced. The common causes of rhabdomyolysis are listed in table 3.

After a review of the patient's differentials, each of the common causes of rhabdomyolysis was carefully excluded. An acute alcoholic myopathy would often present days after a large binge episode, where the patient would remain immobilised and malnourished. A chronic alcoholic myopathy commonly presents in an older individual with a slow and insidious onset. A urine drug screen and history (subjective and collateral) reduced the likelihood that illicit drugs were the causative agents. The history alone was deemed significant enough to rule out any toxic and exertive causes of the rhabdomyolysis. Although selective serotonin reuptake inhibitors (SSRIs) are known to cause rhabdomyolysis, this is regularly on the background of serotonin syndrome, which the presentation did not denote. Her history, clin- 


\section{Case Reports in Neurology}

\begin{tabular}{l|l}
\hline Case Rep Neurol 2016;8:185-192 \\
\hline DOI: 10.1159/000447087 & $\begin{array}{l}\text { @ 2016 The Author(s). Published by S. Karger AG, Basel } \\
\text { www.karger.com/crn }\end{array}$ \\
\hline
\end{tabular}

Bellinge et al.: Sodium Valproate Exacerbating an Underlying Disorder of Fatty Acid Metabolism

ical exam and blood results did not indicate any signs of infection, endocrine disorder, trauma or autoimmune disease.

Sodium valproate is becoming a well-known antagonist in patients with underlying disorders such as mitochondrial disease. Papadimitriou and Servidei [6] in 1991 described a 47-year-old male who presented with a proximal myopathy after 4 months of sodium valproate treatment. A muscle biopsy confirmed the diagnosis of multiple acyl-CoA dehydrogenase deficiency. Kottlors et al. [7] in 2001 described a different 47-year-old male with previous episodes of myoglobinuria, who developed a serious rhabdomyolysis with associated acute kidney injury 4 days after commencing sodium valproate. A muscle biopsy confirmed a CPT-2 deficiency. Njolstad et al. [8] in 1997 described the case of an 11-year-old boy who developed fulminant liver failure with myopathic involvement after being treated with sodium valproate for epilepsy. A diagnosis of medium-chain acyl-CoA dehydrogenase deficiency was made. Similar cases have been described [9-13].

The clinical information mentioned above suggests a vulnerability to the toxic effects of sodium valproate. The patient's history of exercise intolerance, epilepsy, chronic liver disease and rhabdomyolysis supports a disorder of mitochondrial respiratory chain function. From prior case reports, associations between this susceptibility (to sodium valproate) and two inborn errors of mitochondrial metabolism are noted: MCAD deficiency and CPT-2 deficiency. Figure 1 shows the acylcarnitine assay of our patient. This serum analysis is helpful in identifying disorders of the mitochondrial respiratory chain and resulting metabolism of fatty acids. There are significant elevations across most chain lengths of acylcarnitines, but most notable are the elevations in chain lengths C10 and C12. Developing a differential diagnosis from this investigation involves the interpretation of patterns of elevations and deficiencies in differing isomers of the acylcarnitine species. Comparisons are then made between the patterns seen in the patient's blood and classical findings in mitochondrial diseases. Our patient's results are similar to those seen in glutaric aciduria type 2, MCAD deficiency and CPT-2 deficiency. Sodium valproate has been shown to induce abnormal levels of acylcarnitines, though the results seen in our patient have not yet been described $[14,15]$.

The clinical picture of her presentation fits that of a late-onset CPT-2 deficiency. Although this is a likely diagnosis, it cannot be confirmed without a muscle biopsy, to which the patient did not consent.

Using the Naranjo adverse drug reaction probability scale, it is probable that our patient's rhabdomyolysis is due to sodium valproate (Naranjo score +5 ). The key message, however, is not to attribute all responsibility to sodium valproate but rather to consider the likelihood of an underlying mitochondrial disorder in patients exhibiting a severe undifferentiated presentation after commencing this medication.

\section{Statement of Ethics}

Studies on human subjects were conducted in accordance with the Declaration of Helsinki. Accordingly, the authors declare that the subject has given her informed written consent.

\section{Disclosure Statement}

There are no conflicts of interest. 
Bellinge et al.: Sodium Valproate Exacerbating an Underlying Disorder of Fatty Acid Metabolism

\section{References}

1 Skladal D, Halliday J, Thorburn DR: Minimum birth prevalence of mitochondrial respiratory chain disorders in children. Brain 2003;126:1905-1912.

2 Moczulski D, Majak I, Mamczur D: An overview of beta-oxidation disorders. Postepy Hig Med Dosw (Online) 2009;63:266-277.

3 DiMauro S, Schon E: Mitochondrial respiratory-chain diseases. N Engl J Med 2003;348:2656-2668.

4 Chinnery P, Turnbull D: Clinical features, investigation, and management of patients with defects of mitochondrial DNA. J Neurol Neurosurg Psychiatry 1997;63:559-563.

5 Finsterer J, Segall L: Drugs interfering with mitochondrial disorders. Drug Chem Toxicol 2010;33:138151.

6 Papadimitriou A, Servidei S: Late onset lipid storage myopathy due to multiple acyl CoA dehydrogenase deficiency triggered by valproate. Neuromuscul Disord 1991;1:247-252.

-7 Kottlors M, Jaksch M, Ketelsen U, et al: Valproic acid triggers acute rhabdomyolysis in a patient with carnitine palmitoyltransferase type II deficiency. Neuromuscul Disord 2001;11:757-759.

-8 Njolstad PR, Skjeldal OH, Agsteribbe E, et al: Medium chain acyl-CoA dehydrogenase deficiency and fatal valproate toxicity. Pediatr Neurol 1997;16:160-162.

$\$ 9$ Meyer S, Martin T, Loffler G, et al: Severe rhabdomyolysis caused by valproic acid in a neonate with seizures and chromosomal abnormalities. Klin Padiatr 2011;223:434-435.

-10 Kotbi N, Mahgoub N, Mokonogho J, et al: Rhabdomyolysis associated with mania in late life. Int J Geriatr Psychiatry 2009;24:1478-1479.

11 Chattergoon DS, McGuigan MA, Koren G, et al: Multiorgan dysfunction and disseminated intravascular coagulation in children receiving lamotrigine and valproic acid. Neurology 1997;49:1442-1444.

12 Pinkston R, Walker LA: Multiorgan system failure caused by valproic acid toxicity. Am J Emerg Med 1997;15:504-506.

13 Roodhooft AM, Van Dam K, Haentjens D, et al: Acute sodium valproate intoxication: occurrence of renal failure and treatment with haemoperfusion-haemodialysis. Eur J Pediatr 1990;149:363-364.

$\checkmark 14$ Okun J, Kolker S, Schulze A, et al: A method for quantitative acylcarnitine profiling in human skin fibroblasts using unlabelled palmitic acid: diagnosis of fatty acid oxidation disorders and differentiation between biochemical phenotypes of MCAD deficiency. Biochim Biophys Acta 2002;1584:91-98. Rinaldo P, Cowan T, Matern D: Acylcarnitine profile analysis. Genet Med 2008;10:151-156. 


\section{Case Reports in Neurology}

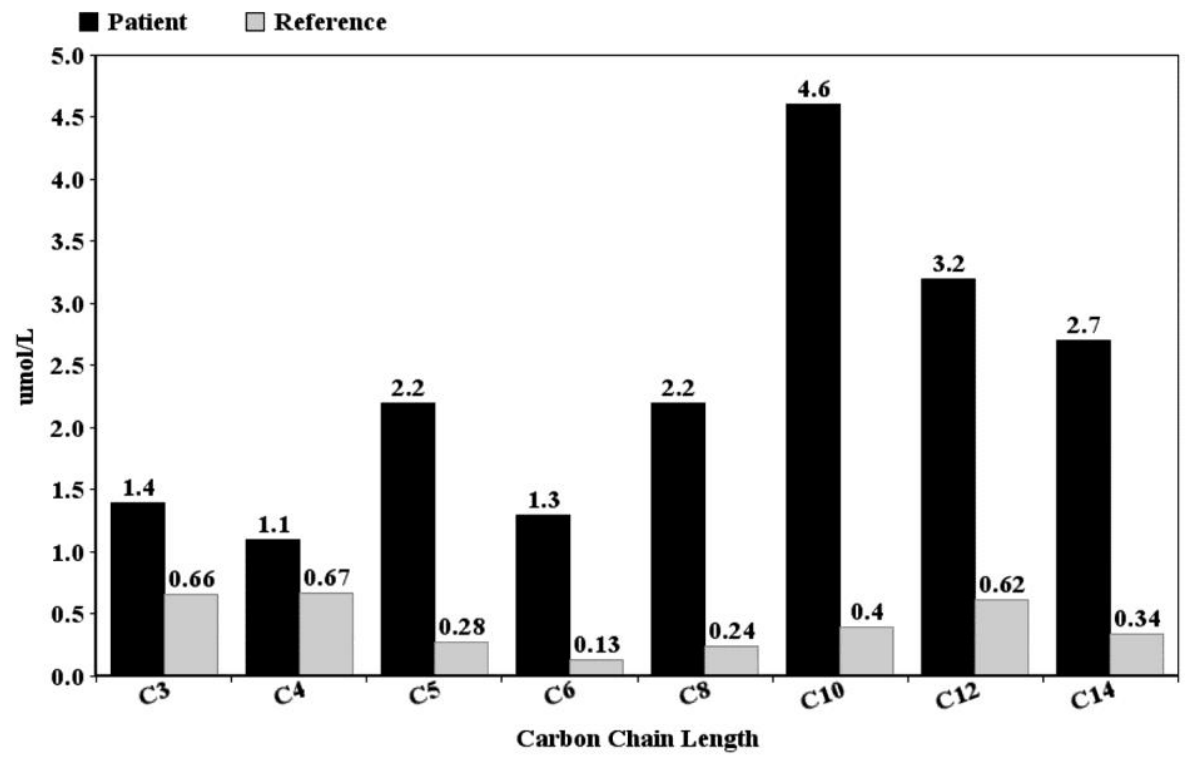

Fig. 1. Results of our patient's acylcarnitine assay. Similar elevations may be seen in other mitochondrial respiratory chain disorders. Additional information can be found in table 2 .

Table 1. Clinical findings in defects of mitochondrial respiratory chain function [2]

\begin{tabular}{ll}
\hline Suggestive symptoms & Reye syndrome (especially recurrent) \\
& Hypotonia and myopathy \\
& Peripheral neuropathy \\
& Altered levels of consciousness \\
& Sudden unexplained death \\
\hline Suggestive findings & Hypoketotic or ketotic hypoglycemia \\
& Cardiomyopathy \\
& Cardiac arrhythmia \\
& Unexplained metabolic acidosis with or without hyperammonemia \\
& Acute fatty liver of pregnancy and HELLP syndrome (haemolysis, elevated \\
& liver enzymes and low platelets) \\
& Recurrent rhabdomyolysis \\
Dicarboxylic aciduria \\
Carnitine deficiency \\
Recurrent/fulminant liver failure
\end{tabular}


Bellinge et al.: Sodium Valproate Exacerbating an Underlying Disorder of Fatty Acid Metabolism

Table 2. Additional information to figure 1

\begin{tabular}{lcl}
\hline Acylcarnitine isomer & $\begin{array}{c}\text { Result, } \\
\mu \mathrm{mol} / \mathrm{l}\end{array}$ & $\begin{array}{l}\text { Reference } \\
\text { range, } \mu \mathrm{mol} / \mathrm{l}\end{array}$ \\
\hline Total carnitine & 182 & $21-70$ \\
Free carnitine & 76 & $13-56$ \\
Acetylcarnitine (C2) & 66 & $3-23$ \\
Propionylcarnitine (C3) & 1.4 & $<0.66$ \\
Tiglylcarnitine (C5:1) & $<0.1$ & $<0.2$ \\
Butyrylcarnitine (C4) & 1.1 & $0.12-0.67$ \\
Isovalerylcarnitine (C5) & 2.2 & $<0.28$ \\
Hexanoylcarnitine (C6) & 1.3 & $<0.13$ \\
3-Hydroxyisovalerylcarnitine (C5-OH) & $<0.1$ & $<0.31$ \\
Octanoylcarnitine (C8) & 2.2 & $<0.24$ \\
Decenoylcarnitine (C10:1) & 0.32 & $<0.5$ \\
Decanoylcarnitine (C10) & 4.6 & $<0.4$ \\
Glutarylcarnitine (C5-DC) & 0.21 & $<0.34$ \\
Dodecanoylcarnitine (C12) & 3.2 & $<0.62$ \\
Tetradecenoylcarnitine (C14:1) & 10 & $<0.73$ \\
Tetradecanoylcarnitine (C14) & 2.7 & $<0.34$ \\
Palmitoylcarnitine (C16) & 2.4 & $<0.65$ \\
3-Hydroxypalmitylcarnitine (C16-OH) & 0.08 & $<0.07$ \\
3-Hydroxybutyrylcarnitine & 0.74 & - \\
Oleoylcarnitine & 6.52 & - \\
3-Hydroxyoleoylcarnitine & 0.13 & - \\
Stearoylcarnitine & 0.78 & - \\
\hline & & \\
\hline
\end{tabular}


Table 3. Common causes of rhabdomyolysis

\begin{tabular}{|c|c|}
\hline Alcohol & $\begin{array}{l}\text { Immobilisation } \\
\text { Direct myotoxicity } \\
\text { Electrolyte disturbances }\end{array}$ \\
\hline $\begin{array}{l}\text { Endocrine } \\
\text { abnormalities }\end{array}$ & $\begin{array}{l}\text { Hypo-/hyperthyroidism } \\
\text { Diabetic ketoacidosis } \\
\text { Non-ketotic hyperosmolar diabetic coma }\end{array}$ \\
\hline Excessive exercise & $\begin{array}{l}\text { Marathon running } \\
\text { Status epilepticus } \\
\text { Acute psychosis } \\
\text { Severe dystonia }\end{array}$ \\
\hline Genetic disorders & $\begin{array}{l}\text { Impaired carbohydrate metabolism } \\
\text { Impaired lipid metabolism }\end{array}$ \\
\hline Illicit drugs & $\begin{array}{l}\text { Cocaine } \\
\text { Heroin } \\
\text { Amphetamines } \\
\text { MDMA }\end{array}$ \\
\hline Immobilisation & $\begin{array}{l}\text { Anaesthesia } \\
\text { Coma } \\
\text { Drug-/alcohol-related unconsciousness }\end{array}$ \\
\hline Infection & $\begin{array}{l}\text { Influenza A and B } \\
\text { Human immunodeficiency virus } \\
\text { Epstein-Barr virus } \\
\text { Coxsackie virus } \\
\text { Cytomegalovirus } \\
\text { Herpes simplex virus }\end{array}$ \\
\hline Medications & $\begin{array}{l}\text { Statins } \\
\text { Fibrates } \\
\text { SSRIs } \\
\text { Lithium } \\
\text { Corticosteroids }\end{array}$ \\
\hline Muscle disease & $\begin{array}{l}\text { Dermatomyositis } \\
\text { Polymyositis }\end{array}$ \\
\hline $\begin{array}{l}\text { Temperature } \\
\text { extremes }\end{array}$ & $\begin{array}{l}\text { Hyper-/hypothermia } \\
\text { Serotonin syndrome } \\
\text { Neuroleptic malignant syndrome } \\
\text { Malignant hyperthermia }\end{array}$ \\
\hline Toxins & $\begin{array}{l}\text { Carbon monoxide } \\
\text { Snake bite } \\
\text { Spider bite } \\
\text { Hemlock }\end{array}$ \\
\hline Trauma & $\begin{array}{l}\text { Crush injuries } \\
\text { Blunt trauma } \\
\text { Electrocution } \\
\text { Severe burns }\end{array}$ \\
\hline
\end{tabular}

